of the more elementary concepts of rock and soil mechanics are included where they are relevant to the analysis of materials or of slope stability. Dr Young is careful to provide a conceptual framework (such as the systems approach) for the ideas which he presents. The last chapter in this book outlines the relevance of slope studies to engineering, agriculture and soil science, and in so doing $\mathrm{Dr}$ Young moves into one of the growth points of the subject, namely applied geomorphology.

Professors Carson and Kirkby adopt a more direct approach to slope form studies through a synthesis of quantitative work in the study of processes and materials. This carries these authors much further into the fields of rock and soil mechanics than is the case with the book by Young. The necessity is seen by Carson and Kirkby for evaluating the dynamic systems of slope processes under different climates by giving them separate treatment in four chapters on humid temperate, periglacial, semiarid and arid, as well as tropical areas. The concluding chapters of their book are concerned with the establishment of theoretical models of the development of slopes in profile, as well as with respect to the situation of slopes within drainage basins. This continues the welcome and refreshing break, adopted by the authors throughout the book, from a merely statistical to a fully mathematical approach to landform studies. It also makes an interesting contrast with Young's concluding emphasis on the practical applications of slope studies.

There are other contrasts apparent between these two books. The series of geomorphology texts to which $\mathrm{Dr}$ Young makes this contribution is aimed at the undergraduate market, while Professors Carson and Kirkby direct their work towards the graduate student. This contrast in level is clear as both books succeed in their stated tasks. Thus to see them as being complementary to each other is not quite fair as they are written for different audiences. Yet it is not possible to read both books without being doubly stimulated by their complementary approaches. Here are two very good books.

\section{J. C. Doornkamp}

\section{Flow Through Soil}

Advanced Soil Physics. By Don Kirkham and W. L. Powers. Pp. xv+534. (Wiley: New York and London, May 1972.) $£ 10$.

Don KIRKhaM is well known to the soil scientist for his numerous papers on seepage of ground water into ditches

\title{
Chesapeake Bay Analogue
}

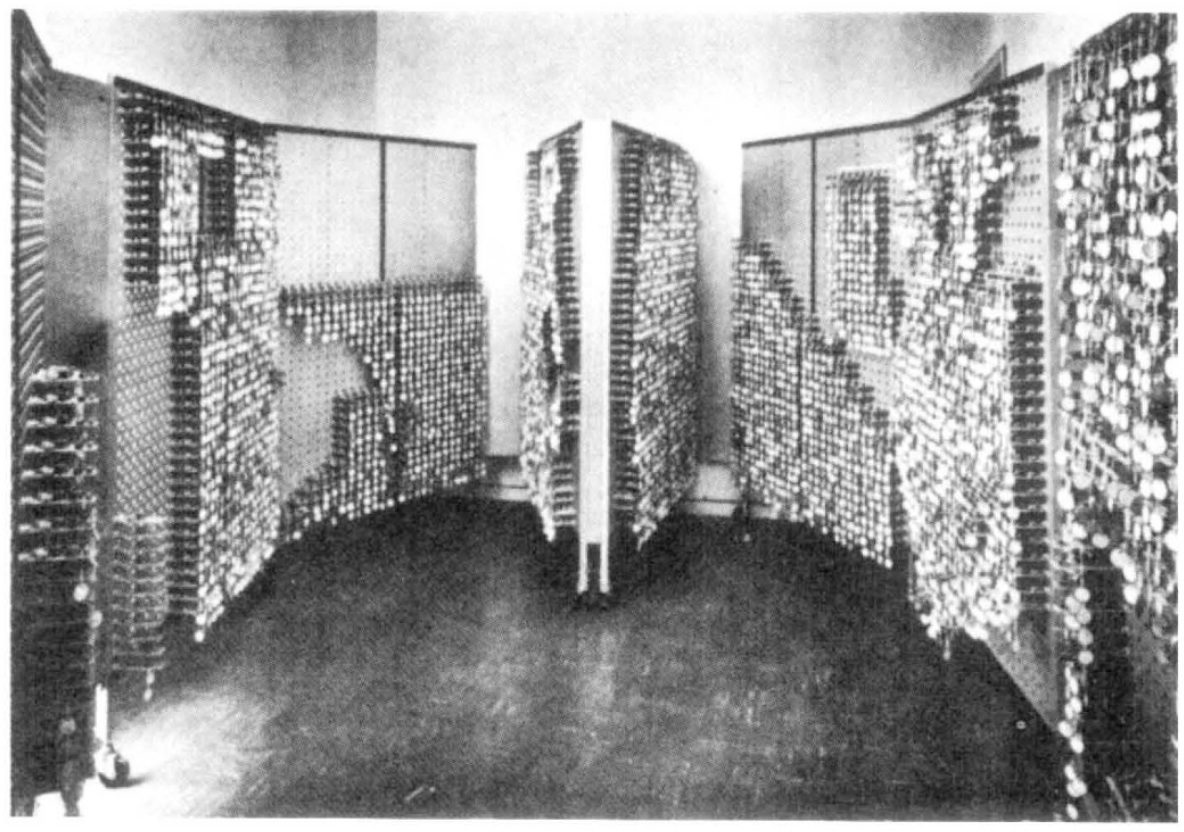

Computer analogue used to investigate the responses of the Chesapeake Bay waters to artificial disturbances. A method described in one of the papers comprising Volume 10 of the annual review of Oceanography and Marine Biology, edited by Harold Barnes (George Allen and Unwin, London, 1972).

and drains and partially penetrating wells. This book, with W. L. Powers, puts these many papers into perspective. After a short introductory chapter on static water in soil we are led straight to Darcy's law, the Laplace equation and the various artifices and techniques used to solve ground-water flow problems. The Schwarz-Christoffel transformation is introduced, and as an example of its use the flow at a corner and into a ditch is analysed. A further chapter deals with unsaturated flow, and J. R. Philip's solution for horizontal and vertical infiltration is described in detail. The final chapters deal with miscible displacement, gaseous diffusion in soils and soil temperature. The book is mathematical in its approach, the more difficult expressions being derived in detail. Each chapter is provided with a set of exercise problems, and there is a good bibliography and list of references.

From this it will be seen that Kirkham and Powers deal primarily with the physics of flow through porous media, and the title they have selected, $A d$ vanced Soil Physics, is therefore somewhat abbreviated. Soil consists of the soil skeleton, plus water and air in the voids, but this book contains almost nothing about the former as might have been expected from the title. It is likely to be of greatest value to research workers in soil physics, hydrology and agricultural engineering who are concerned with ground-water flow, and these will find it excellent.

Kevin NASH

\section{Vibrational Spectra}

Infrared and Raman Spectra of Crystals. By George Turrell. Pp. xii + 384. (Academic: New York and London, September 1972.) £8.50; \$26.50..

ADVANCES in laser Raman spectroscopic and infrared techniques have led to a rapid increase in the number of papers dealing with the infrared and Raman spectra of crystals. Hence this textbook is very timely especially as books by previous authors have considered the dynamics of isolated molecules rather than the cooperative effects which occur in condensed phases. This new guide by Professor Turrell which discusses the interpretation of vibrational spectra of crystalline solids is therefore the first work to discuss the subject in its entirety. The text has grown out of a series of lectures on the theory of vibrational spectroscopy which the author presented at the University of Bordeaux between 1968 and 1970.

The first two chapters review the dynamics and symmetry of molecular vibrations and introduce the matrix formulation which is used throughout the book. For readers who are familiar with the theory of molecular vibrations in isolated molecules, these chapters merely serve to define the notation that is used throughout the book. However, those who are studying the theory of molecular vibrations for the first time should find here the basic material for understanding the later chapters. Little mathematical background is needed 